\title{
Design of Food Professional Talents Cultivation Scheme Based on OBE Concept
}

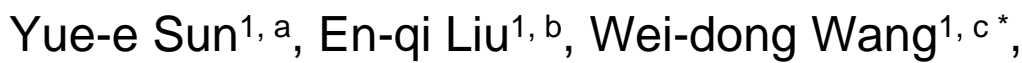 \\ Yu-wei Dong1, d, and Shuai Wang ${ }^{1, e}$
}

School of Food (Biological) Engineering, Xuzhou Institute of Technology Xuzhou 221018, China

asunyuee@163.com, bleq@xzit.edu.cn, cwwd.123@163.com, ddongyuwei66@163.com, e381137786@qq.com

Keywords: Outcomes-based education; Talents cultivation scheme; Food science and technology

\begin{abstract}
The new industrial revolution has put forward new challenges to higher engineering education. What kind of people to cultivate and how to cultivate people are the subject of all engineering colleges and universities. Outcomes-based education is a model of which education and teaching activities is oriented by learning outcomes. It plays an important role in improving the quality of talents cultivation and guides the higher engineering education. Taking the food science and engineering specialty of Xuzhou Institute of Technology as an example, this paper expounded how to set up the training objectives and graduation requirements. On this basis, the curriculum system was optimized and the perfect evaluation system was set up. The in-depth implementation and understanding of the concept of results oriented education, as well as the reverse design talent training program, will help to improve the level of personnel training for engineering college students in China.
\end{abstract}

\section{Introduction}

Professional certification is a specialized certification for the implementation of professional education conducted by professional certification organizations for higher education institutions, and provides quality assurance for related personnel to enter the preparatory education for professional occupations. Engineering education professional certification has been carried out in many countries in the world, and its promotion of the development of engineering education has also been confirmed to a large extent [1]. Establishing a certification system for advanced engineering education has a very important role in improving the international competitiveness of higher engineering education in China and ensuring the quality of higher engineering education in China.

Engineering education professional certification follows three basic concepts: Outcomes-oriented (OBE), student-centered, continuous improvement. These concepts are very important to guide and promote professional construction and teaching reform, and to ensure and improve the quality of personnel training in engineering education. OBE has become the mainstream concept of education reform in the United States, Britain, Canada and other countries. It has been fully adopted by the engineering education certification. It is of practical significance to use the outcomes-oriented education concept to guide the reform of China's engineering education. This article elaborates the process of food science and engineering of Xuzhou Institute of Technology with the concept of OBE, and formulates and implements the talent training program. It provides a reference for the implementation of engineering education concept in China's higher education.

\section{The Concept and Implementation Approach of Outcomes-oriented Education (OBE)}

The Concept of Outcomes-oriented Education. Outcomes-based Education (abbreviated as OBE), also known as competency-oriented education, goal-oriented education or demand-oriented education, first appeared in the basic education reforms in the United States and Australia. OBE 
means that the goal of instructional design and teaching is to achieve the learning outcomes obtained by the students through the education process, and then feedback the results to improve the original instructional design and instructional implementation [2]. The learning outcome is the ultimate ability that the student can eventually achieve after learning through a certain stage. OBE was first proposed by Spady in 1981 and has gained wide attention and application at an astonishing speed. After more than 10 years of development, a relatively complete theoretical system has been formed and it is still considered to be the correct direction for the pursuit of excellence in education.

Ways to Implement Outcomes-oriented Education. The four steps to implement the OBE education model are: defining learning outcomes, achieving learning outcomes, evaluating learning outcomes, and using learning outcomes [3]. OBE is a goal-oriented model for talent cultivation and follows the "reverse design and implementation" approach. The so-called "reverse design" refers to the development of personnel training programs and teaching process, starting from the demand (including internal needs and external needs): demand determines the training objectives, training objectives determine graduation requirements, graduation requirements determine the curriculum system. The course teaching method is determined according to the teaching content, knowledge and ability training requirements of different courses. On the basis of effective guarantees, through multiple evaluations, the evaluation of the accomplishment of talent training results will be formed to form a training program-teaching method-teaching evaluation-a personnel training mechanism for improving and dynamically adjusting the teaching rectification cycle [4].

\section{Practice of OBE Concept in Talent Cultivation}

Determining the Training Objectives Based on Social Needs. According to the standard requirements for engineering education professional certification, the training goal is a general description of the professional and professional achievements students can achieve in about five years after graduation. The basis for formulating training objectives includes both external needs, namely the requirements and expectations of the country, society, employing units, and parents of students. It also includes internal needs, namely the positioning of schools for running schools, the orientation of personnel training, and the pursuit of training quality. In order to better understand the needs of the country and society for talented people, the professional annual visits to employers regularly investigate the needs of their talents and their expectations for graduates. Before formulating the 2015 talent training program, they will study the food science and engineering of our school. Questionnaires were issued for graduates of 2010, 2011 and 2012, and they conducted surveys on the status of their work, opinions and suggestions on the teaching and management of their alma mater. The results of the survey show that graduates of our school's food science and engineering are mainly employed in food or related industries, and most of them are engaged in product development, production management, quality control, and product sales.

When determining educational goals, schools should also base themselves on their own characteristics of running schools, combining the advantages of running schools and the resources they possess. When determining educational goals, schools should also base themselves on their own characteristics of running schools, combining the advantages of running schools and the resources they possess. Xuzhou Institute of technology is a service oriented local undergraduate college, serving the food industry around Xuzhou and other parts of Jiangsu. In addition to the large food enterprises headed by Vivian group, there are still a large number of small and medium-sized enterprises. These small and medium-sized enterprises require a more comprehensive ability, not only to master professional skills, but also need management, sales, and economic theory. Therefore, combined with the results of professional research, we determined that the jobs for students of this major are new product development, production management, quality control and product sales. They should reach the engineer's level in the 5 years or so after graduation, and grow into the middle-level managers or technical backbone of their enterprises (Figure 1). On the basis of mastering basic professional skills, different module courses are set for different positions to meet the knowledge, ability and quality requirements required for the position. 


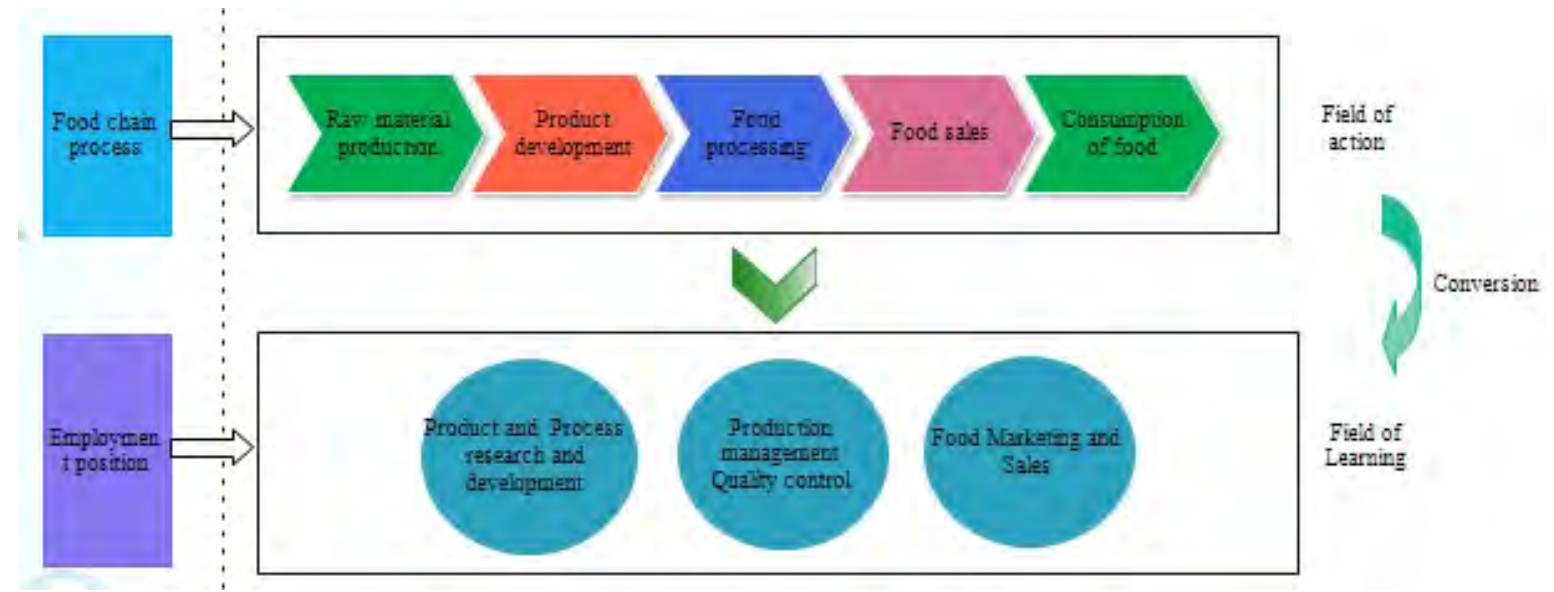

Figure 1. Employment Sector and Position of Graduates in Food Science and Engineering

Providing Support for Training Objectives and Making Graduation Requirements. Graduation requirements are the knowledge, ability and quality requirements that students should achieve when they graduate. It is an effective support for graduates to achieve their training objectives after 5 years. The graduation requirements should be consistent with the training objectives of this major, conform to the professional accreditation standards of engineering education, and have the characteristics of this specialty. For example, the "design / development solution" for the certification standards of engineering education specialty, the graduation requirements of this major are formulated as "the calculation and design of the food factory, the food unit operating equipment, the system, the food processing process, the development of the new food products, and the solutions to the factors affecting the safety of the food." It can also reflect the innovation consciousness in the design link, consider the social, health, safety, legal, cultural and environmental factors, and support the ability to cultivate "product development, production management, quality control" in the training goal.

Graduation requirements must be further refined and decomposed to be operational and measurable, and it is easy to analyze the degree of achievement. When decomposing, relevant requirements of related stakeholders and related industry professional standards should be combined to reflect the subject content, characteristic expression, implementation guidelines, and level of mastery of graduation requirements, and to clarify the main body of implementation. Decomposition index points for the above "design/development solution" graduation requirements are as follows: (1) According to the needs of users, the design goals are determined. Under the constraints of practical conditions such as security, environment, and law, through the evaluation of technical and economical, the feasibility analysis of the design scheme is carried out; (2) Process calculation and equipment design calculation can be performed through modeling; (3) It can integrate the food engineering unit operation process to carry out process design, optimize and improve the design scheme, and reflect innovation consciousness; (4) The product plan can be designed according to requirements and consider social, health, safety, legal, cultural and environmental factors in the plan.

Optimizing Course System Based on Graduation Requirements. Learning outcomes represent a capacity structure that is primarily achieved through curriculum teaching. Therefore, the construction of the curriculum system is particularly important for achieving learning outcomes. There must be a clear mapping relationship between the capability structure and the curriculum structure. Each capability in the capability structure must be supported by a clear curriculum. In other words, each course of the curriculum must have a definite contribution to the realization of the capacity structure. If not, this course will be reconstructed.

According to the training objectives of the food science and engineering professionals of our school, we identify the main positions and tasks of graduates in the food industry chain, and analyze the ability requirements of different positions for graduates, and translate professional post competence requirements into learning areas. The 2015 version of the talent training program has 
built a curriculum system that meets the needs of the talented people in the food industry chain (Figure 2).

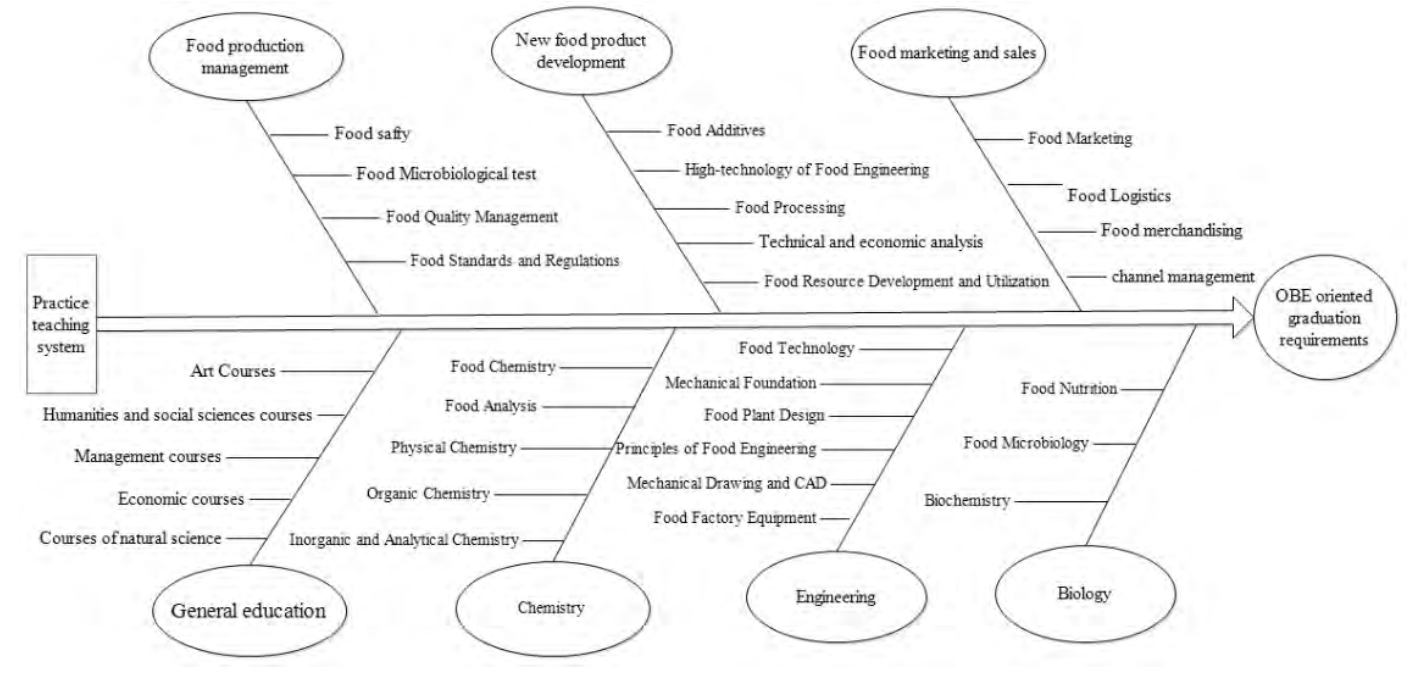

Figure 2. Course system based on OBE

\section{Developing Teaching Strategies Based on Graduation Requirements}

Revision of the Syllabus. Graduation requirements should be implemented one by one in the syllabus of each course to clarify the contribution of the content of the course to the graduation requirements. The outcomes-oriented instructional design requires the preparation of the syllabus. It must firstly make it clear which of the graduation requirements the course will contribute to, and then determine the corresponding teaching content for each of these graduation requirements, and then determine the completion of these teaching. The amount of teaching hours required for the content.

Course Construction. In today's industrial production environment, in order to better align students' learning outcomes with corporate needs, curriculum construction should pay attention to importing corporate resources. Relying on the advantages of local enterprises, our school's food science and engineering major invited Weiwei Group and Haitong Group Xuzhou Co., Ltd. to participate in the construction of the course in order to ensure that the curriculum content is in sync with the needs of industrial talents. In the process of course construction, the enterprise deeply participated in the teaching syllabus, theoretical teaching, practical teaching, graduation design and other links, and timely added the food engineering practice to the teaching content, fully guaranteeing that the course objectives and teaching results are in line with the needs of industry enterprises for talents.

Classroom Teaching. Classroom teaching is still the main form of implementation based on the results-oriented teaching model. Effective classroom teaching is the guarantee that the expected ability is achieved with the established learning goals. It is also the basis for the students to achieve the training goals and meet the graduation requirements [5]. Therefore, in view of the different teaching objectives and teaching contents, different teaching strategies and teaching methods are adopted, from the traditional knowledge imparting to the center to train the students' thinking, innovation and hands-on ability; from traditional instillation type and stuffing style to heuristic, inquiry, discussion and case change; It takes teachers as the main body and shifts to students as the main body. Therefore, for courses such as "Food Analysis" and "Food Factory Design", the major places special emphasis on students' ability to formulate programs, hands-on operations, and analysis results. They use more action-oriented, flipped classroom teaching methods. Through practical project training, theories are internalized to help students develop the ability to find problems and solve problems.

Practical Teaching. In the practice training course, in order to reform the teaching contents and methods, and focusing on the training of students' abilities, the following measures have been taken: (1) Use real job assignments as the carrier, set up practical teaching training programs, and 
prepare practical training outlines so that students can receive real productive practice training in the school; (2) Change the past professional experiment to project teaching. The teacher sets the food analysis, processing, or research and development goals. The students complete the task by "conceiving, designing, realizing, and operating" their own initiative; (3) Emphasize off-campus productive training, arrange students to go to companies for internships in factories, and strengthen the cultivation of students' post-ability and engineering capabilities. By allowing students to go to practical training and internships with food-related companies, students' engineering capabilities have been greatly improved, so that they can achieve zero-distance employment; (4) Encourage students to participate in various national and provincial science and technology competitions and practical training programs, incorporate them into credit management, and strengthen project-driven practical ability development.

Focusing on Learning Outcomes to Build an Evaluation System. The professional regularly evaluates training objectives, graduation requirements, and course objectives. The evaluation focuses on the students' learning outcomes, not on the content of the teaching and the learning time and learning style.

Evaluation of Achievement of Course Teaching Goal. The professional centered on the students' knowledge, ability and quality of engineering practice, designed a new assessment system, and assessed each student's degree of accomplishment in each semester, from focusing on teaching content to paying attention to theory Knowledge, ability and quality. No matter whether it is professional and technical capabilities, or non-technical capabilities such as teamwork and communication, all of them are evaluated quantitatively. Course assessment results are the main source of evaluation data, including job performance, test scores, and so on. All teaching activities support the corresponding graduation requirements indicators. Each test question in the test paper should correspond to the graduation requirements. Figure 4 is an analysis of the degree of achievement of the "Food Nutrition" course, which replaces the distribution of scores in the traditional performance analysis. It can be seen from the figure that the graduation achievement indicator point 3.3 course completion degree evaluation value is 0.37 , and the ratio of the average score and the support score of the final examination achievement grade is 0.55 . This shows that students have a certain gap in the "can be integrated into the food engineering unit operation process design process, optimization and improvement of the design program, reflecting the sense of innovation", and need to further strengthen the training.

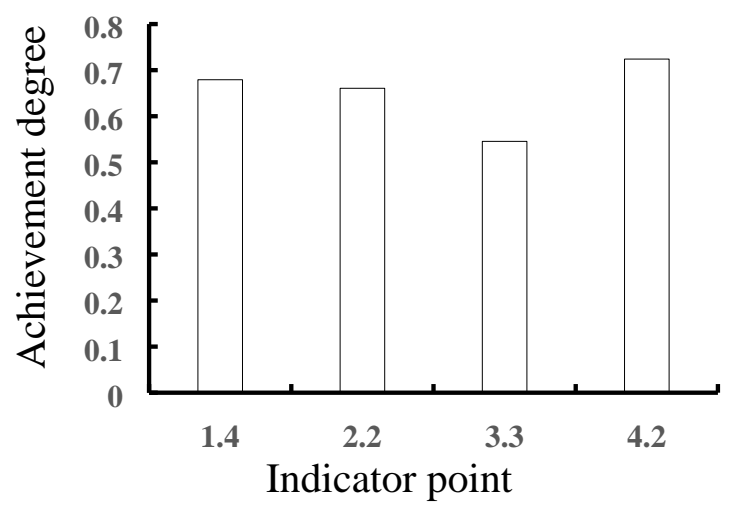

Figure 3. Degree of completion of graduation requirements of Food Nutrition

Graduation Requirement Evaluation. The evaluation of graduation requirements is based on the combination of direct evaluation and indirect evaluation, and the two methods of evaluation are selected. As a major evaluation method of graduation requirements, questionnaire analysis is used as a supplementary evaluation method. The basic data source of the course assessment results analysis method is the evaluation materials for all the courses involved in the graduation requirements, including examination, test, homework, experiment (practice, design) report, course paper, network study and reading report. By examining the supporting relationship between the content of the course examination and its corresponding decomposition index points, the rationality 
of the source of the basic data is ensured. The results of the course examination results analysis were used to evaluate the 2016 graduates of food science and Engineering in our university, and the results showed that students need further improvement and improvement in engineering and society, using modern tools and problem analysis.

\section{Conclusions}

As an advanced educational concept, OBE has formed a relatively complete theoretical system and implementation model, and has been proved in practice to meet the new requirements of Higher Engineering Education in the era of the rapid development of high and new technology at the present stage. OBE is an educational mode that organizes, implements and evaluates personnel training activities with the expectation of learning output as the center. In the process of developing the talent training program, the school should focus on the students' learning results, whether it is the training goal, the graduation requirements or the curriculum system. In the course of teaching, we should aim at the achievement of the students, reform the teaching methods and change from the center of the teacher to the student center, so that the talents trained by the higher engineering education in China are better suited to the needs of the state and the economic and social development.

\section{Acknowledgements}

Fund Project: Brand Specialty Construction Project Funding Project in Jiangsu Universities(PPZY2015B153); Six Talent Peak Projects in Jiangsu(NY-167).

\section{References}

[1] Y. W. Yan, J. Z. Li, X. M. He, etc: Optimization of Active Professional Curriculum System Based on Professional Accreditation of Engineering Education[J]. Science and Technology Innovation Herald, 2015(24): 194-196.

[2] Q. F. Wu, H. X. Li and Y. Shen: Research on Teaching Reform of Higher Engineering Specialty Based on OBE Perspective[J], Education Exploration, 2016 COS) : 97-100.

[3] C. Acharya. Outcome-based Education: a New Paradigm for Learning [J]. CDTLink, 2003, 7(3): 7-9.

[4] F. P. Cao, C. L. Zhao and G. Wang: Construction of Result Oriented Training Mode of Applied Talents[J], Heilongjiang:Higher Educational Research and Evaluation, 2017(4):74-76.

[5] Y. L. Huang: Practice of Achievement Oriented Education in Higher Engineering Education[J], Theoretic Observation, 2016(2): 153-154.

[6] J. Li and Y. Tan: Application of Result Oriented Education in Cultivating Core Competence of Law Students[J], Journal of Liaoning University of Technology (social science), 2017(3):120-122. 